\title{
Medically Significant Hypersensitivity Reaction to Dapsone: A Case Report
}

The drug Dapsone is a component of the World Health Organization multidrug therapy being used against leprosy. Although it has shown a good efficacy during the years, a few subjects develop adverse drug reactions associated with dapsone. We report a case of a patient who was prescribed dapsone as part of multiple drug therapy for leprosy following which he developed Dapsone induced Hypersensitivity Syndrome (DHS). He was prescribed steroids with a tapering dose. His condition worsened after weaning of the oral steroids. He also developed steroid-induced diabetes which was stabilized using anti-diabetic drugs.

KEYWORDS: Dapsone, Hypersensitivity, Sulfone syndrome

\section{INTRODUCTION}

Dapsone has been clinically used for the treatment of leprosy, Tuberculoid or Lepromatous Disease and malaria prophylaxis in some countries. It is a potent anti-inflammatory and antiparasitic compound, and also finds application mainly in the treatment of bullous dermatoses and dermatitis herpetiformis. ${ }^{1}$ It is also being used for erythema elevatum diutinum, epidermolysis bullosa acquisita, linear IgA bullous dermatosis and cicatricial pemphigoid. ${ }^{2}$ The use of dapsone for Pneumocystis carinii pneumonia is still an off label use. While dapsone has demonstrated adequate safety and efficacy in these indications, there are few reports of patients in literature who have developed fatal or life-threatening drug related reactions. ${ }^{3}$ These ADRs with unknown mechanisms are hypersensitivity reactions to the drug and are a part of dapsone syndrome, also known as sulfone syndrome ${ }^{4}$, which is characterized by fever, lymphadenopathy, generalized rash and hepatic involvement as first described by Lowe and Smith. ${ }^{5}$

\section{CASE REPORT}

A 25 year male presented to the hospital with red erythematous maculopapular rash involving trunk, limbs and mucosal membrane for a few days and severe body pain for one week. Generalized lymphadenopathy and bilateral pedal edema were also evident. He had also mild hepatomegaly as per the USG of abdomen along with a history of fever with chills and cough with expectoration. The patient had been taking dapsone and rifampicin daily which had been prescribed by his family physician for leprosy. His chest X-ray was not significant for any finding. The blood picture was only remarkable for leukocytosis. His liver function tests showed elevation in transaminases (aspartate aminotransferase $190 \quad \mathrm{U} / \mathrm{L}, \quad$ alanine aminotransferase $219 \mathrm{U} / \mathrm{L}$ ). The histopathological results revealed mononuclear inflammatory cell infiltration especially in perivascular region with few eosinophils, epidermis revealed mild spongiosis with parakeratotic stratum corneum. He was diagnosed as a case of DHS associated with respiratory tract infection. The patient was prescribed oral prednisolone for once daily use, tablet paracetamol $500 \mathrm{mg}$ twice a day, ceftriaxone, tablet cetrizine, tramadol for pain, and white soft paraffin lotion for local application twice a day. He was also prescribed beclomethasone dipropionate ointment for local application on the erosions. The patient was advised to take tablet prednisolone for 10 days with subsequent tapering of the dose. On this treatment his clinical and hematological condition improved and child was discharged after a week of admission. After stopping the steroid, the patient developed another episode of dapsone syndrome following rebound effect. He was readmitted to the hospital after a month. The patient also developed steroid induced diabetes mellitus. He was prescribed injection insulin $(4 \mathrm{U})$ thrice a day. Intravenous methylprednisolone was started to overcome the relapse of DHS. All the other medications in the previous regimen were restarted except prednisolone. The patient was followed up for 6 months and was in total clinical remission during the last visit. 


\section{DISCUSSION}

With an increase in multidrug therapy for leprosy, there has been a rise in the incidence of DHS. ${ }^{6}$ Dapsone hypersensitivity syndrome is neither dose dependent nor time dependent. Dapsone use can induce hemolytic anemia, ${ }^{3}$ renal injury, ${ }^{7}$ toxic effects on thyroid ${ }^{8}$. Patients experiencing DHS should discontinue the suspect drug immediately and should be managed with topical and systemic steroids, antibiotics, supportive care, nutritional support and fluid replacement. ${ }^{3}$ In the majority of the published literature, the patients' condition improved on permanent discontinuation of the drug and corrective treatment with steroids. ${ }^{8}$ In the present case the condition of the patient worsened as a relapse of DHS was encountered during weaning of the steroids. Moreover, the subject also developed steroid-induced diabetes. DHS has been reported in $0.5 \%-3.6 \%$ of patients taking dapsone and has a mortality rate of $9.9 \%{ }^{3}$ In our case, dapsone was considered to be the probable cause of hypersensitivity due to the specific symptoms. Pharmacokinetic Interaction between Dapsone and Rifampicin has also been reported by Krishna DR et al who detailed that the dapsone level in blood, its half-life and AUC were significantly decreased with simultaneous increase in plasma clearance when it was administered concomitantly along with rifampicin. 9 This kind of interaction could be a possible cause of adverse drug reaction in the present case.

\section{CONCLUSION}

Dapsone is being used widely for a number of diverse conditions across the globe. Healthcare professionals should be aware of this infrequent but potentially life-threatening severe form of adverse event that can prove to be fatal sometimes. Dapsone should be prescribed sensibly and judicious monitoring should be carried out throughout the course of treatment and the management with steroids should not be weaned abruptly.

\section{REFERENCES}

1. Leonard JN, Fry L. Treatment and management of dermatitis herpetiformis. Clin Dermatol 1991;9:403-8.

2. Zhu YI, Stiller MJ. Dapsone and sulfones in dermatology: Overview and update. J Am Acad Dermatol 2001;45:420-34.

3. Lorenz M, Wozel G, Schmitt J. Hypersensitivity reactions to dapsone: A systematic review. Acta Derm Venereol 2012;92:194-9.

4. Park BK, Sanderson JP, Naisbitt DJ. Drugs as haptens, antigens and implications. In: Pichler WJ, editor. Drug Hypersensitivity Basel: Karger, 2007: p. 55-65.

5. Lowe J, Smith M. The chemotherapy of leprosy in Nigeria; with an appendix on glandular fever and exfoliative dermatitis precipitated by sulfones. Int J Lepr 1949;17:181-95.

6. Richardus JH, Smith TC. Increased incidence in leprosy of hypersensitivity reactions to dapsone after introduction of multidrug therapy. Lepr Rev 1989;60:267-73.

7. Alves-Rodrigues EN, Ribeiro LC, Silva MD, Takiuchi A, Fontes CJ. Dapsone syndrome with acute renal failure during leprosy treatment: Case report. Braz J Infect Dis 2005;9:84-6.

8. Gupta A, Eggo MC, Uetrecht JP, Cribb AE, Daneman D, Rieder MJ, et al. Drug-induced

hypothyroidism: The thyroid as a target organ in hypersensitivity reactions to anticonvulsants and sulfonamides. Clin Pharmacol Ther 1992;51:56-67. 9. Krishna DR, Appa Rao AVN, Ramanakar TV,Prabhakar MC.Pharmacokinetic Interaction Between Dapsone and Rifampicin in Leprosy Patients. Drug Dev Ind Pharm 1986; 12(1):443-459.

Source of support: Nil, Conflict of interest: None declared

Cite this article as:

Sharma B. Medically Significant Hypersensitivity Reaction to Dapsone: A Case

Report. Int Healthcare Res J 2018;2(1):10-11. doi: 10.26440/IHRJ/o2_01/157

\section{AUTHOR AFFILIATIONS:}

1. MBBS, Senior Lecturer, General Medicine, Shri Sukhmani Dental College and Hospital, Dera Bassi, Mohali, Punjab, India

\section{Corresponding Author:}

Dr. Bharat Sharma

MBBS, Senior Lecturer, General Medicine

Shri Sukhmani Dental College and Hospital

Dera Bassi, Mohali, Punjab
For article enquiry/author contact details, e-mail at: manuscriptenquiry.ihrj@gmail.com 